\title{
Research on Innovation of Floating Production Storage and Offload- ing Unit's Rent Mode under Low Oil Price
}

\author{
Jinyan Xue ${ }^{1^{*}}{\text { Wenwen } \mathrm{Li}^{2}}^{2}$ Mingjun Tang ${ }^{2}$ Hongjuan Wu ${ }^{1}$ Bin Zhou ${ }^{1}$ \\ 1. CNOOC Energy Technology \& Service Oil Production Service Co., Beijing, 100027, China \\ 2. CNOOC Energy Technology \& Services Limited., Beijing, 100027, China
}

\begin{tabular}{l}
\hline ARTICLE INFO \\
\hline Article history \\
Received: 22 July 2020 \\
Revised: 29 July 2020 \\
Accepted: 9 October 2020 \\
Published Online: 16 October 2020 \\
\hline Keywords: \\
Low oil price \\
Floating production storage and offloading \\
unit \\
Rent mode \\
Oilfield economic life
\end{tabular}

\section{Introduction}

$\mathrm{F}$ loating Production Storage and Offloading, hereinafter referred to as FPSO, is an "Offshore Oil Plant" which integrates the functions of production, processing, storage and offloading. It is the offshore oil production unit which is widely applied currently. It has the characteristics of high technology, large application range and long life cycle. Along with the continuous progress of technology, the operation

\begin{abstract}
After many years of exploitation, onshore oil and gas resources are about to enter a recession period. Oil and gas will mainly come from oceans in the future. Generally speaking, the exploration and production (E\&P) cost of oil from offshore is much higher than that of oil from onshore, so it is more sensitive to oil price. However, in recent years, oil price has been hovering at a low level for a long time, almost close to or even lower than the E\&P cost of oil, which directly affects the development of oilfields. Besides the influence of oil price, some oilfields present the characteristics of marginal reserve scale, short peak production period and output rapidly declining. There leads to short economic life period and makes the economic benefit close to or lower than oilfield's hurdle rate, which increases the difficulty of offshore oilfield development. As an important part of oilfield development, Floating Production Storage and Offloading unit, its investment mode and rent mode directly affect overall oilfield's rate of return and the economic life. This paper chooses lease mode as the research object based on the analysis of investment mode, and further puts forward rent mode related with oil price through the analysis of traditional rent mode, and illustrates the advantages and disadvantages of various rent modes and their applicability so that the lessor chooses the right mode to achieve Win-Win with Oil Company and promotes the development of oilfields under low oil price.
\end{abstract}

scope and ability of FPSO are expanding and improving continually, which has become the mainstream means of offshore oil and gas development for different water depth and different environmental conditions ${ }^{[1]}$. The concept ship, FAST4WARD, is built in bulk. It realizes the standardization of FPSO's construction and delivery, reduces the cost of construction, and accelerates the period of delivery, which make the application of FPSO more rapid.

According to survey data of 2018 Global Floating Pro-

*Corresponding Author:

Jinyan Xue,

CNOOC Energy Technology \& Service Oil Production Service Co., Beijing, 100027, China;

E-mail:xuejy2@cnooc.com.cn. 
duction Storage and Offloading Units (FPSO), the number of global FPSO in service was 183 by the end of 2018 . According to International Maritime Association (IMA) analysis, the order number of FPSO is 32 to 58 from 2019 to the end of 2023 , and the most likely number is 49 , and $30-35 \%$ of projected FPSO over the next five years will be used in Brazil. Hence, the market demand of FPSO is still very broad ${ }^{[2]}$.

\section{Analysis on FPSO's Investment Mode}

FPSO is a capital intensive industry, and its construction requires high initial funding and large amounts of financing. The total investment in oilfield development mainly includes exploration expenditure, development investment, oilfield operation cost and discard expense. FPSO's investment accounts for $20-40 \%$ of oilfield's total investment, so it is crucial for oilfield development ${ }^{[3]}$.

FPSO investor, namely shipowner, is divided into two categories: one is oil companies, such as CNOOC, currently 16 FPSOs in China, 8 of which is owned by CNOOC. The other is FPSO professional operators, such as SBM, MODEC, BW Offshore, and Bumi Armanda. CNOOC Energy Technology \& Services Limited is the only professional operator in China with 8 FPSOs, and ranks fifth among the global FPSO operators. Nowadays, oil companies in the world are more and more inclined to lease FPSO from operators. FPSO's investment, construction and operation is taken by Operators. On the one hand, through leverage, oilfield's overall rate of return can be increased, on the other hand, it avoids taking up a large amount of funds early to affect oil company's cash flow, at the same time, reduces the risk of oil company's investment and operation. Oil Company can concentrate on oil exploration, development, production and sales ${ }^{[4]}$. At present, the number proportion of Oil Company's own and lease is $50 \%$, not only in China, both also in the world, and there is also an upward trend in the future to lease FPSO, which is a rare development opportunity for professional operators. This paper only analyzes FPSO's lease mode, and does not consider the mode that FPSO is invested by Oil Companies.

\section{Analysis on FPSO's Traditional Rent Mode}

Oil price has fallen sharply since 2014 and keep low for five years, which have exhausted major international oil companies. Cost decreasing and benefit increasing is also difficult to meet the demands of oilfield development.

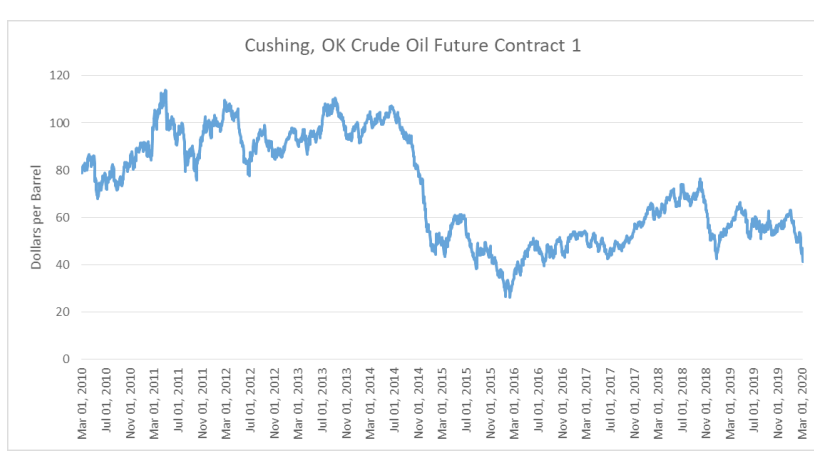

Data source: US Energy Information Administration website (EIA https://www.eia.gov/).

Figure 1. Crude Oil Futures Contract Price of Cushing in the last decade

Besides the influence of oil price, at present, the exploitation of some offshore oilfields also take on the following characteristics:

1) Crude oil price approaches oil operation cost, and oilfield development's economic benefit is critical to the hurdle rate.

2) The scale of oilfield reserves tends to be marginalized, and it also shows the characteristics of short peak yield period and output rapidly declining, which causes oilfield's short economic life period ${ }^{[5]}$.

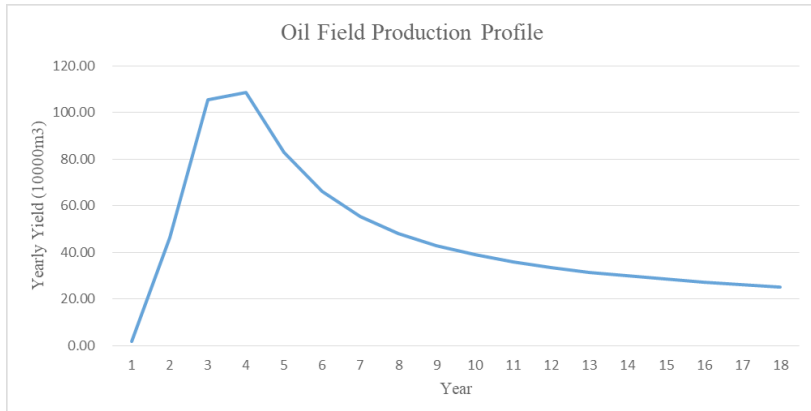

Figure 2. Current typical offshore oilfield yield profile

Normally, FPSO's lease term is consistent with the economic life period of the target oilfield, and its investment accounts for a large proportion of oilfield's total investment. Therefore, FPSO's rent mode is very important for oilfield's economic life period and economic benefit.

Nowadays, FPSOs in service outside China only adopts the mode of full fixed rent, while FPSOs in service within China mainly adopts the mode of both full fixed rent and fixed rent plus bonus on barrel.

Under the full fixed rent mode, FPSO's rent has nothing to do with the oilfield output and oil price, and the lessor will not bear the risk caused by the actual output of the oilfield which is lower than expected and low oil price. Therefore, they have stable revenue. This is the least risk mode. However, in this mode, the pressure is also the 
greatest for oil companies, oilfield's economic life period may be further shortened by comparing the mode FPSO invested by oil companies, and in the period of oil price's large fluctuations or low keeping, actual oilfield revenue is lower than expected, which reducing the confidence of oil companies to develop target oilfields. However, in fact, fixed rent mode of FPSO in China is often not absolutely fixed, in the oilfields with a rapid decline in output, a stepped rent mode which is high in front and low in back can ensure that the economic life of the oilfields will not be significantly reduced, but also FPSO's lessors can recover investment quickly.

Under fixed rent plus bonus on barrel, partial rent is related with the oilfield output, which conforms to the oilfield output trend. Compared with the full fixed rent mode, the economic life period of the oilfield can be extended appropriately, and the pressure caused by the uncertainty of oilfield output can be reduced. For FPSO's lessors, under the premise of ensuring the minimum revenue, although taking some risks of oilfield output, they enjoy the extra benefits brought by excess production.

The influence of FPSO rent on the economic life of oilfields mainly depends on the revenue proportion between fixed portion and bonus portion. As an example of the oilfield production trend in Fig. 2, the effect of two rent modes on the economic life of the oilfield is simulated and analyzed. According to Fig. 3, the mode of fixed rent plus bonus on barrel can extend the economic life period of the oilfield for 2 years by comparing full fixed rent mode. For the purpose of showing more clearly the effect of production bonus on the economic life of the oilfield, the ultimate state that rent is linked entirely with output is presented. Provided that other conditions are invariant, this rent mode completely conforms to the trend of the oilfield and can extend the economic life period of the oilfield for another two years. However, this mode is too risky for FPSO's lessors, so it is not recommended to adopt it.

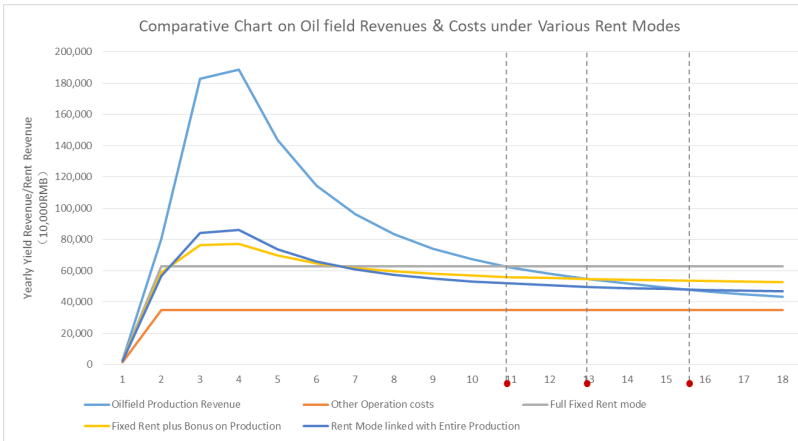

Figure 3. Comparative Chart on Oil field Revenues \& Costs under Various Rent Modes

\section{Study on FPSO Rent Mode Related with Oil Price}

Nowadays, with the development of oilfield exploration technology, oilfield operators have gradually transferred the worries from the uncertainty of oilfield output to that of oil price, so it is time to put forward FPSO's rent mode related with oil price.

Principles for the design of rent mode related with oil price:

1) For lessors, the risk is controllable and the revenue is guaranteed;

2) And lessors and Oil Companies could reach WinWin, and jointly promotes oilfield development ${ }^{[6]}$.

Based on these principles, the rent is divided into two parts: fixed rent and bonus on oil price. Fixed rent can be determined by the required rate of return plus downward floating point, which is regarded as the basic rate of return, downward floating point can be confirmed by the assessment of oil price risk.

On the basis of fixed portion, Bonus on oil price is setup by two steps:

Step 1: According to the expected oilfield output distribution, calculate the bonus on barrel at the range of benchmark oil price, so that internal rate of return reaches the required rate of return.

Step 2: Determine the benchmark oil price range or the benchmark oil price point by the average oil price within a certain period. After that, consider the extreme cases to determine the upward and downward floating oil price points in order to get the maximum and minimum. So that in the extreme cases during all period of operation, when the real-time oil price is lower than the minimum or is higher than the maximum, both the lessor and oil company can accept the losses under this mechanism.

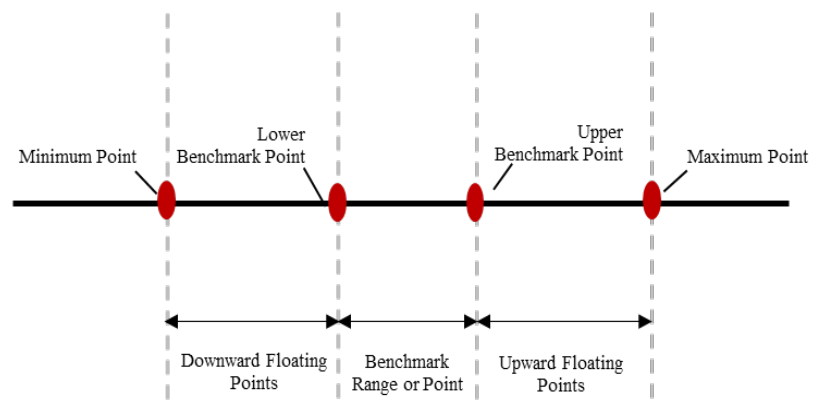

Figure 4. Oil price range diagram

Assuming that the actual output of the oilfield is not taken into account, that is, the actual output is consistent with the expected, the revenues linked with oil price is analyzed as follows. 
1) When real-time oil price is within the range of minimum point and lower benchmark point.

When real-time oil price is less than minimum point, the real-time oil price in the formulas equals to the minimum point, and revenue linked with Oil Price is 0 , that is, only fixed rent is collected.

Revenue linked with Oil Price

$=$ Bonus on barrel at the range of Benchmark Oil Price

$\times\left[1+\frac{1}{\text { Downward Floating Points }} \times(\right.$ Realtime Oil Price - Upper Benchmark Point $\left.)\right]$

2) When real-time price is at or within the benchmark range

Revenue linked with Oil Price is equal to bonus on barrel under the benchmark oil price. Benchmark oil price can be showed in the form of interval or point, if point, the upper and lower benchmark oil price points overlap.

3) When real-time oil price is within the range of upper benchmark point and maximum point.

Revenue linked with Oil Price

$=$ Bonus on barrel at the range of Benchmark Oil Price

$\times\left[1+\frac{1}{\text { Upper Floating Points }} \times(\right.$ Realtime Oil Price - Upper Benchmark Point $\left.)\right]$

When real-time oil price is higher than maximum point, the real-time oil price in the formulas equals to maximum point.

For operability, two key points should be also determined in practice: one is the source of real-time oil price, which can be adopted the price of Cushing crude oil futures. Cushing crude oil futures price is the pricing point of West Texas Intermediate (WTI) futures which is the world's largest trading volume. WTI is the primary crude specified for delivery to Cushing, OK under the NYMEX futures contract. Therefore, the comparable inventory in Cushing is the key factor dominating the global oil price, so it is reasonable to choose the Cushing crude oil futures contract price as real-time oil price ${ }^{[7]}$. Another is the method of determining the real-time oil price. Generally speaking, FPSO's rent is settled at the end of the month and paid at the beginning of next month, so we can consider calculating the monthly average oil price as the real-time as a cycle from the previous settlement date to the current settlement date ${ }^{[8]}$.

Normally, before first oil, oilfield's output is based on the distribution data provided by the oil company. If the output is constant, that is, only bonus on oil price, the lowest rate of return is the same as confirmed basic rate of rate. In practice, both parties come to an agreement that the output is subject to the actual, which can realize the revenue linked with both barrel and oil price.

\section{Analysis on Rent Mode's Advantages \& Disadvantages and Applicability}

The rent modes mentioned in this paper are analyzed with the advantages $\&$ disadvantages and applicability, so that FPSO's lessor could choose the right mode according to the details of oilfield.

\subsection{Full Fixed Rent Mode}

Advantage: For FPSO's lessor, the revenue is stable and the risk is minimal.

Disadvantage: Compared with Oil Company as shipowner, the rent will reduce the economic life of the oilfield, and then affect the oilfield benefit.

This mode is applicable to oilfields with high rate of return and the output slowly declining, and the lessor is lack of confidence in expected production and future crude oil price.

\subsection{Fixed Rent Plus Bonus on Barrel}

Advantage: (1) For FPSO's lessor, on the basis of ensuring the basic revenue, when the actual output is higher than expected, they can get extra profits. (2) The economic life period of the oilfield can be extended appropriately compared with full fixed rent mode.

Disadvantage: The lessor takes a certain risk of production.

This mode is applicable to oilfields with the hurdle rate achieved and the output fast declining, and the lessor is optimistic about expected production and pessimistic about future crude oil price.

\subsection{Fixed Rent Plus Bonus on Only Oil Price}

Advantage: (1) Based on ensuring the basic revenue, FPSO's lessor can obtain the extra profits brought by high oil price. (2) it can ensure the continued exploitation of oilfields under sustained low oil price. (3) it can extend the economic life of the oilfield to a certain extent.

Disadvantage: FPSO's lessor bears a certain risk of low oil price.

This mode is applicable to oilfields with the hurdle rate achieved and the output fast declining, and the lessor has confidence in long-term higher crude oil price.

\subsection{Fixed Rent Plus Bonus on Both Barrel and Oil Price}

Advantage: (1) Based on ensuring the basic revenue, FPSO's lessor can obtain the extra profits caused by high production and high oil price. (2) it can ensure the continued exploitation of oilfields under sustained low oil price and low production. (3) it can prolong the economic life of 
the oilfield.

Disadvantage: the lessor takes risks of low oil price and low production.

This mode is applicable to oilfields with the hurdle rate achieved and the output fast declining, and the lessor is optimistic about both expected production and future crude oil price.

\section{Conclusion}

Based on the analysis of the traditional rent mode, this paper puts forward the rent mode linked with oil price which can realize the risks sharing and benefits sharing with oil company under ensuring the basic revenue of FPSO's lessor and promote the development of oilfields under low oil price, according to the current trend of oil price and the current characteristics of oilfields.

\section{References}

[1] Li Huai-yin. The CAPEX Estimating Methodology of Offshore Oilfield Petroleum Engineering [J]. Value Engineering. 2011(27):56-57.

[2] Methods and parameters for economic evaluation of construction projects (third edition)[M].Beijing: China Planning Press, 2006.

[3] Wu Jia-ming. Distinguishing Feature and Existing Circumstances of FPSO [J]. SHIP ENGINEERING. 2012(02):156.

[4] Li Xin-zhong, Tan Yue. Discussion on Development Engineering Modes for Offshore Oil and Gas Fields [J]. Petroleum Engineering Construction. 2015(01):01-04

[5] Xue Jinyan, Gao Wei, Wang Dongyue. Method for Determining Investment Project's Required Rate of Return on FPSO [J]. Construction \& Design for Project. 2019(22):243-245.

[6] Liu Yin-sheng. Basic theory of project cost management and related laws [M].Beijing:China Planning Press. 2009.

[7] Liu Xue-quan, Li Jun. Construction and model realization of financial evaluation system of investment project. Journal of Industrial Technological Economics, 2007(26):134-137.

[8] Huo Li-jun, Zhou Peng. Recent review and forecast of international oil prices [J]. International Petroleum Economics. 2019(27):10-14. 